\title{
Are we working to save the species our children want to protect? Evaluating species attribute preferences among children
}

\author{
Kristin Frew, M. Nils Peterson and Kathryn Stevenson
}

\begin{abstract}
As conservation resources decline and numbers of threatened species increase, prioritizing species for conservation is increasingly important, and prioritizing based on attributes may be the most efficient approach. Despite the importance of biodiversity as a legacy to future generations, children's preferences for species attributes have never been considered. We surveyed $3 \mathrm{rd}$ and 5 th grade students, typically 8-10 years old, in North Carolina, USA, to determine how children prioritize conservation of species based on attributes. We asked the students to rank five species attributes, allocate money to species with each attribute, and choose between each species attribute and endemism in terms of their importance for conservation. Children prioritized species that are important in nature and those whose numbers are declining over species with other attributes, whereas research suggests that adults prioritize endemic species over most other types. Our results suggest children prioritize biodiversity conservation differently from adults, and in ways that may be more conducive to biodiversity conservation in cases where endemism is not directly related to species endangerment, and we suggest the perspectives of children be considered more fully within biodiversity conservation.
\end{abstract}

Keywords Children, conservation priorities, environmental education, species attributes, valuation

\section{Introduction}

D rioritizing species for conservation is increasingly im1 portant as the resources available for biodiversity conservation are limited and often declining (Mace et al., 2007; Butchart et al., 2010) and conservation needs are increasing (Pereira et al., 2010; Cardinale et al., 2012; Hooper et al., 2012). Human actions have increased extinction rates by up to 1,00o times their background levels (Pimm et al., 1995), and this catastrophe is projected to worsen as a result of rapid anthropogenic climate and land cover change

Kristin Frew (Corresponding author), M. NiLs Peterson and Kathryn Stevenson Fisheries, Wildlife, and Conservation Biology Program, Department of Forestry and Environmental Resources, North Carolina State University, Box 8001, Raleigh, NC 27695, USA. E-mail knfrew@ncsu.edu

Received 7 July 2015. Revision requested 16 September 2015.

Accepted 23 December 2015. First published online 4 May 2016.
(Foley et al., 2005; Leadley et al., 2010; Bellard et al., 2012). Fixed or declining conservation budgets (Iwamura et al., 2010; Waldron et al., 2013) will necessitate trade-offs regarding which species are protected. Many government organizations and conservation NGOs prioritize species based on their risk of becoming extinct (e.g. the U.S. Endangered Species Act of 1973; the IUCN Red List, 2015); however, some scientists suggest that other attributes need to be considered when deciding conservation priorities. Experts have used criteria including endemism, economic value, ecological significance, charisma and evolutionary distinctiveness to prioritize species for conservation (Avise, 2005; Isaac et al., 2007; Sodhi et al., 2010; Curnick et al., 2015). The importance of species that have significant impacts on ecological and evolutionary processes has also been highlighted (Possingham et al., 2002; Isaac et al., 2007; Arponen, 2012).

Understanding public perspectives on prioritizing species is critical because saving species often requires human intervention, and public preference should influence conservation in nominally democratic contexts (Czech et al., 1998). Public preferences dictate where money is allocated, which species receive protection, and the overall success of conservation plans (Norton, 1986; Martín-López et al., 2007, 2009). Efforts to evaluate public prioritization of biodiversity conservation have focused on willingness to pay for conserving a species or suite of species (e.g. Loomis \& White, 1996; Martín-López et al., 2007). However, such studies tend to be species specific and do not provide general principles for prioritizing species. Eliciting public preference for species conservation can be problematic when using named species because public preference for iconic species tends to overestimate species' value (Jacobsen et al., 2008). Furthermore, stakeholders may vary widely in their perceptions of specific species; for example, the tiger Panthera tigris is a popular flagship species in developed countries but those whose lives and livelihoods are threatened by tigers have a different view (Leader Williams \& Dublin, 2000). Researchers have responded to this need to elicit public preferences by developing and testing the importance of several relatively objective and general species attributes (e.g. Knegtering et al., 2002; Montgomery, 2002; Meuser et al., 2009). Being rare and endemic are often considered to be the most important species attributes (Veríssimo et al., 2009; Morse-Jones et al., 2012; Takahashi et al., 2012). Body size and appearance are also relevant attributes for 
flagship species but their importance varies among studies (Takahashi et al., 2012; Veríssimo et al., 2014). One study ranked endemic species as the highest conservation priority, followed by species with declining numbers and species of economic importance (Meuser et al., 2009).

This research trajectory focusing on multiple species attributes is important but conspicuously omits the perspectives of children. The idea that biodiversity conservation is in part about a bequest to our children and future generations is axiomatic to the field of conservation biology and has been voiced repeatedly (Weiss, 1990; Meine et al., 2006). Furthermore, the future success of conservation efforts depends on creating the next generation of conservationists. Experiences in childhood can set lasting trajectories in areas such as academic performance (Gelman \& Brenneman, 2004), success (Gorey, 2001) and pro-environmental behaviour (Chawla, 1999), and understanding the opinions of children may elucidate how to foster lifelong stewardship of biodiversity. Children influence their parents in areas such as purchasing behaviour (e.g. convincing parents to buy particular breakfast cereals; Flurry \& Burns, 2005), information technology (e.g. teaching parents computer skills; Hampshire, 200o), and pro-environmental behaviour (e.g. encouraging parents to recycle; Legault \& Pelletier, 2000), which suggests that children's conservation priorities may influence those of their parents. For all these reasons the perspectives of children are fundamentally important in prioritizing biodiversity conservation.

We studied how children prioritized species attributes (cf. Meuser et al., 2009), hypothesizing that they would rank species with declining numbers and ecologically important species highest. Although previous studies among adults found endemism to be an important, if not the most important, attribute (Meuser et al., 2009; Veríssimo et al., 2009; Morse-Jones et al., 2012), this finding may be attributable to adults having a nativist response to animals, similar to xenophobia towards other people (Brown \& Sax, 2004), which may lead to favouritism for native animals, including endemic species. Although gender is a relatively strong and persistent driver of how adults prioritize and perceive wildlife (Kellert \& Berry, 1987; Czech et al., 2001), we predicted the relationship would be weaker among children because gender identities are still forming (Serbin et al., 1993; Martin \& Ruble, 2004, 2009). We treated ethnicity, socio-economic status and education as exploratory variables because there was little or no theory suggesting potential relationships between these variables and how children prioritized species for conservation.

\section{Methods}

Sampling We targeted 3 rd and 5 th grade students, typically 8-10 years old, in North Carolina, USA, because they represented the youngest age groups with cognitive abilities to think abstractly and form interests and concerns related to environmental issues (Gelman \& Brenneman, 2004). We obtained a stratified random sample of children from elementary schools across North Carolina, selecting 60 schools from a list of all public middle and elementary schools in the state. From a list of all 3 rd and 5 th grade teachers in these 60 schools we randomly selected 118 teachers for participation in our study. Of the 118 teachers contacted, 36 responded (30.5\% response rate) and 21 consented to participate ( $58.3 \%$ compliance rate). Data were collected via 440 surveys administered to students during 16 classroom visits in March 2014 (all students who attended class chose to participate). The decision to survey only 16 of the 21 classes that consented to participate was based on scheduling conflicts. Gender was balanced ( $53 \%$ female) and most students were in the 3 rd grade $(79 \%)$. The most prevalent ethnicity was white $(46 \%)$, followed by African American (21\%), Native American (11\%), Hispanic (10\%), other (10\%) and Asian (2\%). School-level data from the National Center for Education Statistics indicated that the mean percentage of students eligible for free or subsidized lunches at the schools in our sample was $66.4 \pm$ SD 17.5\% (U.S. Department of Education, 2012). The North Carolina State University institutional review board (IRB \#3793) approved this study, and all participants gave their informed consent to participate.

Questionnaire design To elicit children's species preferences we constructed a questionnaire asking them to rank species attributes, allocate money to species with each attribute, and choose between each species attribute and endemism in terms of importance for conservation. The questions were adapted for children from a similar survey by Meuser et al. (2009). We chose this approach both to facilitate comparisons and because other methods (e.g. choice experiments) were less suited to minimizing classroom time interrupted by the study and minimizing cognitive difficulty for the age group involved (Hanley et al., 2001). Firstly, students were asked to rank the importance of five species attributes that could determine the allocation of resources for conservation: wild animals whose numbers are declining rapidly (species with declining numbers), wild animals that are important in nature (species important in nature), wild animals that live nowhere else but North Carolina (endemic species), wild animals that people like to watch (species people watch), and wild animals that people like to eat (species people eat). Secondly, students were asked to allocate a specific amount of money (USD 10) among the same species attributes. This constant-sum question provided a ranking of attributes and a measure of children's preferences for these attributes. Thirdly, students were asked to choose between endemic species and four other species 
TABLE 1 Responses of 3 rd and 5th grade students in North Carolina, USA, to three species attribute preference tasks. All species attributes compared to endemism (i.e. wild animal species that live only in North Carolina) using the Wilcoxon signed-rank test.

Task 1: Rank each kind of species from 1 (should be protected first) to 5 (should be protected last)

\begin{tabular}{llr}
\hline Species attribute & Mean rank & $Z^{1}$ \\
\hline Species whose numbers are declining rapidly & 2.05 & $10.21^{*}$ \\
Wild animal species that are important in nature & 2.39 \\
Wild animal species that people like to eat & 3.17 \\
Wild animal species that live only in North Carolina & 3.57 \\
Wild animal species that people like to watch & 3.81 \\
\hline
\end{tabular}

Task 2: Allocate a total of USD 10 for protection of the five species attributes

\begin{tabular}{lll}
\hline Species attribute & Mean allocation (USD) & $Z^{2}$ \\
\hline Wild animal species whose numbers are declining rapidly & 2.99 & $-9.83^{*}$ \\
Wild animal species that are important in nature & 2.25 & $-6.01^{*}$ \\
Wild animal species that people like to eat & 1.78 \\
Wild animal species that live only in North Carolina & 1.65 \\
Wild animal species that people like to watch & 1.43 & $3.982^{*}$ \\
\hline
\end{tabular}

Task 3: \% of cases in which each species attribute was chosen over endemism

\begin{tabular}{llc}
\hline Species attribute & $\%$ preferred over endemic & $Z^{3}$ \\
\hline Wild animal species that are important in nature & $91.23 \%$ & $29.91^{\star}$ \\
Wild animal species whose numbers are declining rapidly & $86.16 \%$ & $21.41^{*}$ \\
Wild animal species that people like to eat & $51.42 \%$ & 0.58 \\
Wild animal species that people like to watch & $46.79 \%$ & -1.32 \\
\hline
\end{tabular}

${ }^{1}$ Associated with comparison to endemic species $\left(H_{0}=\right.$ no difference in rank of species attributes; $\left.n=296\right)$

${ }^{2}$ Associated with comparison to endemic species $\left(\mathrm{H}_{\mathrm{o}}=\right.$ no difference in rank of species attributes; $\mathrm{n}=333$ )

${ }^{3}$ Associated with comparison to endemic species $\left(\mathrm{H}_{\mathrm{o}}=\right.$ no difference in rank of species attributes; $\left.\mathrm{n}=424\right)$

*Significant, with $\alpha<0.0125$ corrected for false discovery rate (Benjamini \& Hochberg, 1995)

attributes (species with declining numbers, species important in nature, species people watch, and species people eat). For each pair, the students identified the attribute they thought should be a higher priority for species protection. The final instrument was based on pre-testing the students. We administered the draft instrument to two classes of 5 th grade students $(n=32)$. We asked them to circle questions that were difficult to understand, and make notes on how they could be improved. After adjusting the wording of several items we administered a second draft of the survey to two classes of 3 rd grade students $(n=37)$ and asked for written feedback. Additionally, we conducted cognitive interviews (Desimone \& Le Floch, 2004) with 12 students to gather general feedback and identify versions of questions that were easier to understand.

Analysis For the first two questions (ranking species attributes and allocating money to species with each attribute) we compared students' answers using Wilcoxon signed-rank tests (Meuser et al., 2009). For the question asking students to choose between each species attribute and endemism we tested for differences in the pairwise comparisons using binomial tests. For each question we also explored whether students' preferences differed by grade level, gender, ethnicity, locale and socio-economic status, using Mann-Whitney U tests. For socio-economic status we split the sample based on the median percentage of students eligible for free or subsidized lunches (65.6\%). Students attending schools below the median were placed in the high socio-economic status group and students attending schools at or above the median were placed in the low socio-economic status group. We also used school-level locale data to split the sample into urban and rural students. Those attending schools in areas classified as rural or towns were placed in the rural group, and those in suburbs or cities were placed in the urban group. School-level socio-economic and locale data were obtained from the National Center for Education Statistics (U.S. Department of Education, 2012).

\section{Results}

When asked to rank species attributes, and allocate money to species with each attribute, children ranked species with declining numbers as most important (Table 1). Species with declining numbers were ranked higher and allocated more money than species with all other attributes except species important in nature. When asked to choose between each species attribute and endemism, children chose species 
TABLE 2 Responses of 3 rd and 5th grade students in North Carolina, USA, to three species attribute preference tasks, with Mann-Whitney U tests $(Z)$ comparing rankings of each species attribute between the two grades.

Task 1: Rank each kind of species from 1 (should be protected first) to 5 (should be protected last)

\begin{tabular}{llll}
\hline & Mean rank & \\
\cline { 2 - 3 } Species attribute & 3 3rd Grade & 5th Grade \\
\hline Species whose numbers are declining rapidly & 2.37 & 1.93 & $2.98^{*}$ \\
Species that are important in nature & 2.80 & 2.22 & $3.31^{*}$ \\
Species that people like to eat & 2.96 & 3.24 & -1.52 \\
Species that live only in North Carolina & 3.22 & 3.73 & $-2.57^{*}$ \\
Species that people like to watch & 3.60 & 3.89 & -1.94 \\
\hline
\end{tabular}

Task 2: Allocate a total of USD 10 for protection of the five species attributes

\begin{tabular}{llll}
\hline & Mean allocation (USD) & 5th Grade \\
\cline { 2 - 3 } Species attribute & 3rd Grade & 3.13 & $-2.93^{*}$ \\
\hline Species whose numbers are declining rapidly & 2.57 & 2.23 & -0.15 \\
Species that are important in nature & 2.31 & 1.77 & 0.14 \\
Species that people like to eat & 1.84 & 1.53 & $2.64^{*}$ \\
Species that live only in North Carolina & 1.94 & 1.42 & 0.66 \\
Species that people like to watch & 1.46 & \\
\hline
\end{tabular}

Task 3: \% of cases for which each species attribute was chosen over endemism

\begin{tabular}{llll}
\hline & \% preferred over endemic & & \multirow{2}{*}{$Z^{3}$} \\
\cline { 2 - 3 } Species attribute & 3rd Grade & 0.89 & $-3.03^{*}$ \\
\hline Species whose numbers are declining rapidly & 0.78 & 0.93 & -1.4 \\
Species that are important in nature & 0.88 & 0.51 & $-2.42^{*}$ \\
Species that people like to eat & 0.42 & 0.47 & $3.132^{*}$ \\
Wild animals that people like to watch & 0.59 & \\
\hline
\end{tabular}

${ }^{1}$ Associated with comparison of rankings based on grade level $\left(H_{o}=\right.$ no difference in rank of species attributes; $\left.n=293\right)$

${ }^{2}$ Associated with comparison of rankings based on grade level $\left(\mathrm{H}_{\mathrm{o}}=\right.$ no difference in rank of species attributes; $\left.\mathrm{n}=333\right)$

${ }^{3}$ Associated with comparison of rankings based on grade level $\left(\mathrm{H}_{\mathrm{o}}=\right.$ no difference in rank of species attributes; $\left.\mathrm{n}=42 \mathrm{O}\right)$

*Significant, with $\alpha<0.0125$ corrected for false discovery rate (Benjamini \& Hochberg, 1995)

important in nature over endemic species (Table 1), giving second preference to species with declining numbers.

We did not detect gender-based differences in ranking of species attributes, allocation of money to species with each attribute, or choices between each species attribute and endemism. Comparing education level we found children in the $3 \mathrm{rd}$ grade $(n=347)$ and 5 th grade $(n=93)$ ranked species attributes in the same order but with different strengths of preference. The 5 th grade students ranked species with declining numbers and species important in nature significantly higher than those in the 3 rd grade (Table 2). The 3 rd grade students ranked endemic species higher than those in the 5th grade. The 5th grade students allocated more money to species with declining numbers than those in the 3 rd grade, and 3rd grade students allocated more money to endemic species than those in the 5th grade. When asked to choose between each species attribute and endemism 3 rd grade students chose species people watch over endemic species more often than 5 th grade students, and 5 th grade students chose species people eat over endemic species more than 3 rd grade students (Table 2). Third grade students demonstrated higher variance in their ranking of endemic species ( $\mathrm{SD}=1.46 \mathrm{vs} 1.23$ ), species people eat ( $\mathrm{SD}=1.51 \mathrm{vs} 1.34$ ) and species important in nature $(\mathrm{SD}=1.41 \mathrm{vs} 1.31)$.

We did not detect a difference in the overall ranking of species attributes or the allocation of money to species with each attribute between white $(n=196)$ and non-white children $(n=229)$. However, examining individual attributes we found that white children ranked species with declining numbers higher than non-white children (Table 3). White children also allocated more money to species with declining numbers than non-white children. Non-white children allocated more money to conserving species people watch than white children. When asked to choose between each species attribute and endemism white children chose species with declining numbers over endemic species more often than nonwhite children (Table 3). Patterns in overall ranking and allocation of money between students attending schools in the low $(n=273)$ and high $(n=172)$ socio-economic status groups largely mirrored those evident when comparing white and non-white students (Table 3). This is reasonable as ethnicity was strongly related to socio-economic status in 
TABLE 3 Responses of 3rd and 5th grade students in North Carolina, USA, to three species attribute preference tasks, by ethnicity and school socio-economic status (SES), with Mann-Whitney U tests $(Z)$ comparing rankings of each species attribute between ethnicities and socioeconomic status.

Task 1: Rank each kind of species from 1 (should be protected first) to 5 (should be protected last)

\begin{tabular}{|c|c|c|c|c|c|c|}
\hline \multirow[b]{2}{*}{ Species attribute } & \multicolumn{6}{|c|}{ Mean rank } \\
\hline & White & Non-white & $Z^{1}$ & Low SES & High SES & $Z^{2}$ \\
\hline Species whose numbers are declining rapidly & $1.72^{*}$ & $2.32^{*}$ & -4.39 & $1.44^{\star}$ & $0.81^{\star}$ & 5.43 \\
\hline Species that are important in nature & 2.29 & 2.48 & -0.92 & 1.49 & 1.33 & 0.07 \\
\hline Species that people like to eat & 3.27 & 3.08 & 1.03 & 2.18 & 2.16 & 0.35 \\
\hline Species that live only in North Carolina & 3.66 & 3.50 & 0.59 & 2.39 & 2.69 & -1.34 \\
\hline Species that people like to watch & $4.07^{\star}$ & $3.60^{*}$ & 3.23 & $2.52^{*}$ & $2.99^{\star}$ & -2.45 \\
\hline
\end{tabular}

Task 2: Allocate a total of USD 10 for protection of the five species attributes

\begin{tabular}{|c|c|c|c|c|c|c|}
\hline \multirow[b]{2}{*}{ Species attribute } & \multicolumn{6}{|c|}{ Mean allocation (USD) } \\
\hline & White & Non-white & $Z^{3}$ & Low SES & High SES & $Z^{4}$ \\
\hline Species whose numbers are declining rapidly & $3.18^{\star}$ & $2.83^{\star}$ & 2.55 & 2.59 & $3.20^{\star}$ & -1.04 \\
\hline Species that are important in nature & 2.24 & 2.26 & 0.55 & 2.42 & 2.16 & 1.60 \\
\hline Species that people like to eat & 1.76 & 1.79 & 0.02 & 1.78 & 1.78 & 1.16 \\
\hline Species that live only in North Carolina & 1.61 & 1.63 & -0.61 & 1.72 & 1.62 & 1.78 \\
\hline Species that people like to watch & $1.29^{*}$ & $1.57^{\star}$ & -3.51 & $1.61^{*}$ & $1.34^{*}$ & 5.03 \\
\hline
\end{tabular}

Task 3: \% of cases for which each species attribute was chosen over endemism

\begin{tabular}{|c|c|c|c|c|c|c|}
\hline \multirow[b]{2}{*}{ Species attribute } & \multicolumn{6}{|c|}{$\%$ preferred over endemism } \\
\hline & White & Non-white & $Z^{5}$ & Low SES & High SES & $Z^{6}$ \\
\hline Species whose numbers are declining rapidly & $0.96^{*}$ & $0.78^{\star}$ & 1.48 & $0.74^{*}$ & $0.93^{\star}$ & -5.28 \\
\hline Species that are important in nature & 0.93 & 0.89 & 5.27 & 0.89 & 0.92 & -1.15 \\
\hline Species that people like to eat & 0.55 & 0.48 & 1.52 & $0.54^{*}$ & $0.43^{\star}$ & 2.12 \\
\hline Species that people like to watch & 0.45 & 0.48 & -0.58 & $0.42^{*}$ & $0.57^{\star}$ & -2.96 \\
\hline
\end{tabular}

${ }^{1}$ Associated with comparison of rankings based on ethnicity $\left(H_{0}=\right.$ no difference in rank of species attributes; $\left.n=288\right)$

${ }^{2}$ Associated with comparison of rankings based on socio-economic status $\left(\mathrm{H}_{\mathrm{o}}=\right.$ no difference in rank of species attributes; $\left.\mathrm{n}=296\right)$

${ }^{3}$ Associated with comparison of rankings based on ethnicity $\left(H_{o}=\right.$ no difference in rank of species attributes; $\left.n=331\right)$

${ }^{4}$ Associated with comparison of rankings based on socio-economic status $\left(\mathrm{H}_{\mathrm{o}}=\right.$ no difference in rank of species attributes; $\left.\mathrm{n}=331\right)$

${ }^{5}$ Associated with comparison of rankings based on ethnicity $\left(H_{o}=\right.$ no difference in rank of species attributes; $\left.n=293\right)$

${ }^{6}$ Associated with comparison of rankings based on socio-economic status $\left(\mathrm{H}_{\mathrm{o}}=\right.$ no difference in rank of species attributes; $\left.\mathrm{n}=419\right)$

${ }^{*}$ Significant with $\alpha<0.0125$ corrected for false discovery rate (Benjamini \& Hochberg, 1995)

the study area (Macartney et al., 2013). Children from the high socio-economic status group placed more importance on species with declining numbers and less importance on species people watch than did the low socio-economic status group (Table 3). Children at high socio-economic status schools also allocated less money to species people watch, than children at low socio-economic status schools. When asked to compare each attribute to endemism, students in the high socio-economic status group chose species with declining numbers and species people eat more often, and species people watch less often, than the students at the low socioeconomic status schools (Table 3 ).

\section{Discussion}

In contrast with research involving adults (Meuser et al., 2009), the children surveyed did not consider endemism to be the most important species attribute. They ranked endemic species as fourth most important, below species with declining numbers, species important in nature and species people eat. This outcome could be a result of children having less prejudice against alien species than adults. It has been theorized that implicit racial prejudice develops via exposure to detrimental socializing agents in early childhood (Devine, 1989; Sinclair et al., 2005). Adults may have a deep natural response, similar to xenophobia towards people, in how they perceive alien plants and animals (Brown \& Sax, 2004). Children may be less influenced by this nativist thinking because they have yet to develop prejudices against people, animals or plants that are seen as foreign (Brown \& Sax, 2004). Social desirability may have influenced our findings because endemism was the only variable used in multiple comparisons in the last question, perhaps suggesting that researchers cared more about it. However, this seems unlikely as we used three measures to test species attribute 
preferences and they yielded the same results despite the last question being the only one potentially vulnerable to social desirability bias.

The children prioritized species attributes in much the same way a conservation biologist would. Although conservation biologists have not reached consensus about which species attributes are most important (Wilson et al., 2011), species with declining or threatened populations and those with large ecological or evolutionary roles are typically given top priority (Carter et al., 2000; Forest et al., 2007; Isaac et al., 2007; Redding et al., 2010). These attributes are the ones the children valued above all others. Being endemic, fun to watch or edible may have some value but if species with these attributes face no threats to future population viability and do not play a critical role in ecosystem function, why dedicate resources to protecting them? As the perspectives of children often influence their parents, from purchasing (Flurry \& Burns, 2005; Walia Sharma \& Dasgupta, 2009) to pro-environmental behaviours (Easterling et al., 1995; Ballantyne et al., 1998, 2001; Duvall \& Zint, 2007; Damerell et al., 2013), the conservation perspectives of children may be leveraged to influence adults who may prioritize less critical species attributes. Conversely, some of the greatest wildlife conservation challenges require eradication of non-native species, such as feral cats (Ash \& Adams, 2003; Robertson 2008; Loss et al., 2013), and typical arguments justifying elimination of species on the basis of non-native or invasive status may not resonate as well among children as among adults.

Unlike studies that identified gender effects on species preferences among adults (Meuser et al., 2009; Veríssimo et al., 2009), we did not find any correlations between gender and prioritization of any species attributes. Although there are many gender development theories rooted in diverse biological and social schema, it is widely accepted that the development of gender identity is a dynamic process that is far from complete among children of elementary school age (Bussey \& Bandura, 1999), and this may explain our lack of findings regarding gender differences in species attribute preferences among children. Social cognitive theory combines psychological and socio-structural determinants to explain gender development as a product of familial and social influences encountered regularly (Bussey \& Bandura, 1999). These relationships shape the development of gender identity from as early as $\mathbf{2}$ years old until a person is in their 20 ; however, gender development is a dynamic process that can continue throughout life (Martin \& Ruble, 2009; Leman \& Tenenbaum, 2011). Future research may therefore detect gender effects on species attribute preferences in young adults as they gain societal experience. Studies among older students (aged 10-20 years) have identified gender effects, with girls being more oriented towards pets (Bjerke et al., 1998) and more fearful of animals, particularly threatening species (Prokop \& Tunnicliffe, 2010; Prokop \& Fančovičová, 2013).
Future research should explore when gender identity begins to influence preferences for species and species attributes.

Differences in grade level, ethnicity and socio-economic status did not correspond to differences in species attribute rankings but were related to differences in mean ranking for some attributes. Our finding that 5 th grade students prioritized species with declining numbers more than 3 rd grade students indicates that 2 more years of schooling may result in increased knowledge regarding the environment and how organisms are interconnected (Kellert, 1984; Larson et al., 2010). This may correspond with species prioritization approaching a conservation biology ideal. Alternatively, 3 rd grade students demonstrated more variance in their answers, which could be a result of not being able to read as well and having a less clear understanding of the questions. If this is the case, better reading comprehension could produce results similar to those for 5 th grade students. A previous study among adults found that those with a higher level of education had a greater preference for endemic species (Meuser et al., 2009); however, the contrast with our results may reflect a difference in the way education level was measured in the two studies.

The relationships between ethnicity and species attribute preferences may be explained by previously established differences in attitudes towards wildlife among ethnic groups; for example, non-white children were found to be more utilitarian than white children (Kellert, 1984). Although recent research among children is limited, research suggests the same pattern has persisted over time among adults (Tarrant \& Cordell, 2002; Brown, 2003; Manfredo et al., 2003; Teel et al., 2005). Because such utilitarian attitudes identified among non-white adults also exist among children, this could explain our finding that non-white children considered edibility and watchability to be more important species attributes than white children. These findings should be interpreted with caution, however, as ethnicity serves as a surrogate for other variables, such as income, education and the incidence of single-parent households (Collins, 2004; Duncan \& Magnuson, 2005). The fact that our results relating to socio-economic status mirrored those relating to ethnicity supports the assertion that ethnicity may serve as a surrogate for socio-economic status in this case. Research indicates that nature-based education may improve environmental literacy more among minority than non-minority students in the USA (Stevenson et al., 2013), and therefore exploring the degree to which similar experiences shape the balance between use-focused and conservation-focused attributes for species conservation would be valuable.

Differences in students' preferences for species attributes depending on the socio-economic status of their schools may parallel studies linking affluence with pro-environmental attitudes and behaviours among adults (Van Liere \& Dunlap, 1980; Scott \& Willits, 1994; Chen et al., 2013). This line of research suggests that individuals become more 
concerned with the environment after their material needs have been met and they shift towards attending to aesthetic needs (Inglehart, 1995). Our results suggest that children of low socio-economic backgrounds may have a more utilitarian interest in wildlife (e.g. having a stronger preference for species people watch) and those of higher socio-economic backgrounds may be interested in biodiversity conservation for its own sake (e.g. a stronger preference for species with declining numbers). Although our measure of socioeconomic status was at the school level, these results warrant future research as this is the first study we are aware of that has investigated how socio-economic status influences children's wildlife conservation priorities.

Further research on how children prioritize species attributes would benefit from consideration of several variables, including geographical location of homes (Miller, 2005), significant life experiences in nature (Stevenson et al., 2014), and adult role models (Monroe, 2003), which appear to shape the way children orient themselves towards nature and potentially biodiversity. Similarly, unique geographical contexts, such as islands, may elicit particular species attribute rankings among children (e.g. higher ranking for endemic species) and should be considered. Future research with older children may benefit from choice experiment methodology because it facilitates more realistic trade-offs between species attributes (Hanley et al., 2001; Veríssimo et al., 2009; Di Minin et al., 2013). Qualitative research would provide insight into why children think certain species attributes are more important than others. To combat declining global biodiversity, public awareness of the need to preserve biological diversity is crucial. Species attribute preferences among children may provide the foundation for a bridge between the preferences of the public and those of conservation biologists for prioritizing conservation efforts.

\section{Acknowledgements}

We thank R. Noss for giving us the idea for this research, E. Meuser, H. Harshaw and A. Mooers for explaining their work with Canadian adults, K. Gutierrez, L. Maynard and the 2014 Human Dimensions of Wildlife class at North Carolina State University for their help with data collection, and the teachers and students who participated in this study.

\section{References}

Arponen, A. (2012) Prioritizing species for conservation planning. Biodiversity and Conservation, 21, 875-893.

Ash, S.J. \& Adams, C.E. (2003) Public preferences for free-ranging domestic cat (Felis catus) management options. Wildlife Society Bulletin, 31, 334-339.
Avise, J.C. (2005) Phylogenetic units and currencies above and below the species level. In Phylogeny and Conservation (eds A. Purvis, J.L. Gittleman \& T. Brooks), 76-100. Cambridge University Press. Cambridge, UK.

Ballantyne, R., Connell, S. \& Fien, J. (1998) Students as catalysts of environmental change: a framework for researching intergenerational influence through environmental education. Environmental Education Research, 4, 285-298.

Ballantyne, R., Fien, J. \& Packer, J. (2001) Program effectiveness in facilitating intergenerational influence in environmental education: lessons from the field. The Journal of Environmental Education, 32, $8-15$.

Bellard, C., Bertelsmeier, C., Leadley, P., Thuiller, W. \& Courchamp, F. (2012) Impacts of climate change on the future of biodiversity. Ecology Letters, 15, 365-377.

Benjamini, Y. \& Hochberg, Y. (1995) Controlling the false discovery rate: a practical and powerful approach to multiple testing. Journal of the Royal Statistical Society, 57, 289-300.

Bjerke, T., ØdegÅrdstuen, T.S. \& Kaltenborn, B.P. (1998) Attitudes toward animals among Norwegian children and adolescents: species preferences. Anthrozoos, 11, 227-235.

Brown, J.H. \& SAX, D.F. (2004) An essay on some topics concerning invasive species. Austral Ecology, 29, 530-536.

BROWN, S.E. (2003) Ethnic variations in pet attachment among students at an American school of veterinary medicine. Society \& Animals, 11, 101-102.

Bussey, K. \& Bandura, A. (1999) Social cognitive theory of gender development and differentiation. Psychological Review, 106, 676-713.

Butchart, S.H.M., Walpole, M., Collen, B., van Strien, A., Scharlemann, J.P.W., Almond, R.E.A. et al. (2010) Global biodiversity: indicators of recent declines. Science, 328, 1164-1168.

Cardinale, B.J., Duffy, J.E., Gonzalez, A., Hooper, D.U., Perrings, C., Venail, P. et al. (2012) Biodiversity loss and its impact on humanity. Nature, 486, 59-67.

Carter, M.F., Hunter, W.C., Pashley, D.N. \& Rosenberg, K.V. (2000) Setting conservation priorities for landbirds in the United States: the partners in flight approach. The Auk, 117, 541-548.

Chawla, L. (1999) Life paths into effective environmental action. The Journal of Environmental Education, 31, 15-26.

Chen, X., Peterson, M.N., Hull, V., Lu, C., Hong, D. \& Liu, J. (2013) How perceived exposure to environmental harm influences environmental behavior in urban China. Ambio, 42, 52-60.

Collins, F.S. (2004) What we do and don't know about 'race', 'ethnicity', genetics and health at the dawn of the genome era. Nature Genetics, 36, S13-S15.

Curnick, D.J., Head, C.E.I., Huang, D., Crabbe, M.J.C., Gollock, M., Hoeksema, B.W. et al. (2015) Setting evolutionary-based conservation priorities for a phylogenetically data-poor taxonomic group (Scleractinia). Animal Conservation, 18, 303-312.

Czech, B., Devers, P.K. \& Krausman, P.R. (2001) The relationship of gender to species conservation attitudes. Wildlife Society Bulletin, 29, 187-194.

Czech, B., Krausman, P.R. \& Borkhataria, R. (1998) Social construction, political power, and the allocation of benefits to endangered species. Conservation Biology, 12, 1103-1112.

Damerell, P., Howe, C. \& Milner-Gulland, E.J. (2013) Child-orientated environmental education influences adult knowledge and household behaviour. Environmental Research Letters, 8, 015016.

Desimone, L.M. \& Le Floch, K.C. (2004) Are we asking the right questions? Using cognitive interviews to improve surveys in education research. Educational Evaluation and Policy Analysis, 26, $1-22$. 
Devine, P.G. (1989) Stereotypes and prejudice: their automatic and controlled components. Journal of Personality and Social Psychology, 56, 5-18.

Di Minin, E., Fraser, I., Slotow, R. \& Macmillan, D.C. (2013) Understanding heterogeneous preference of tourists for big game species: implications for conservation and management. Animal Conservation, 16, 249-258.

Duncan, G.J. \& Magnuson, K.A. (2005) Can family socioeconomic resources account for racial and ethnic test score gaps? The Future of Children, 15, 15-34.

Duvall, J. \& Zint, M. (2007) A review of research on the effectiveness of environmental education in promoting intergenerational learning. The Journal of Environmental Education, $38,14-24$.

Easterling, D., Miller, S. \& Weinberger, N. (1995) Environmental consumerism: a process of children's socialization and families' resocialization. Psychology \& Marketing, 12, 531-550.

FluRry, L.A. \& BURnS, A.C. (2005) Children's influence in purchase decisions: a social power theory approach. Journal of Business Research, 58, 593-601.

Foley, J.A., DeFries, R., Asner, G.P., Barford, C., Bonan, G., Carpenter, S.R. et al. (2005) Global consequences of land use. Science, 309, 570-574.

Forest, F., Grenyer, R., Rouget, M., Davies, T.J., Cowling, R.M., Faith, D.P. et al. (2007) Preserving the evolutionary potential of floras in biodiversity hotspots. Nature, 445, 757-76o.

Gelman, R. \& Brenneman, K. (2004) Science learning pathways for young children. Early Childhood Research Quarterly, 19, $150-158$.

Gorey, K.M. (2001) Early childhood education: a meta-analytic affirmation of the short- and long-term benefits of educational opportunity. School Psychology Quarterly, 16, 9-30.

Hampshire, M. (2000) Lost in cyberspace. The Times Educational Supplement, 4381, 30-31.

Hanley, N., Mourato, S. \& Wright, R.E. (2001) Choice modelling approaches: a superior alternative for environmental valuation? Journal of Economic Surveys, 15, 435-462.

Hooper, D.U., Adair, E.C., Cardinale, B.J., Byrnes, J.E.K., Hungate, B.A., Matulich, K.L. et al. (2012) A global synthesis reveals biodiversity loss as a major driver of ecosystem change. Nature, 486, 105-108.

Inglehart, R. (1995) Public support for environmental protection: objective problems and subjective values in 43 societies. PS: Political Science and Politics, 28, 57-72.

Isaac, N.J.B., Turvey, S.T., Collen, B., Waterman, C. \& Baillie, J.E.M. (2007) Mammals on the EDGE: conservation priorities based on threat and phylogeny. PLoS ONE, 2(3), e296.

Inamura, T., Wilson, K.A., Venter, O. \& Possingham, H.P. (2010) A climatic stability approach to prioritizing global conservation investments. PLoS ONE, 5(11), e15103.

Jacobsen, J.B., Boiesen, J.H., Thorsen, B.J. \& Strange, N. (2008) What's in a name? The use of quantitative measures versus 'Iconised' species when valuing biodiversity. Environmental and Resource Economics, 39, 247-263.

Kellert, S.R. (1984) Attitudes toward animals: age-related development among children. Advances in Animal Welfare Science, 1, 43-6o.

Kellert, S.R. \& Berry, J.K. (1987) Attitudes, knowledge, and behaviors toward wildlife as affected by gender. Wildlife Society Bulletin, 15, 363-371.

Knegtering, E., Hendrickx, L., Van Der Windt, H.J. \& Uiterkamp, A.J.M.S. (2002) Effects of species' characteristics on nongovernmental organizations' attitudes toward species conservation policy. Environment and Behavior, 34, 378-40o.
Larson, L.R., Castleberry, S.B. \& Green, G.T. (2010) Effects of an environmental education program on the environmental orientations of children from different gender, age, and ethnic groups. Journal of Park \& Recreation Administration, 28, 95-113.

Leader Williams, N. \& Dublin, H.T. (2000) Charismatic megafauna as 'flagship species'. In Priorities for the Conservation of Mammalian Diversity: Has the Panda had its Day? (eds A. Entwistle \& N. Dunstone), pp. 53-81. Cambridge University Press, Cambridge, UK.

Leadley, P., Pereira, H.M., Alkemade, R., FernandezManjarres, J.F., Proença, V., Scharlemann, J.P.W. \& Walpole, M.J. (2010) Biodiversity Scenarios: Projections of 21st Century Change in Biodiversity and Associated Ecosystem Services. Secretariat of the Convention on Biological Diversity, Montreal, Canada, CBD Technical Series no. 50, 132 pp.

Legault, L. \& Pelletier, L.G. (2000) Impact of an environmental education program on students' and parents' attitudes, motivation, and behaviours. Canadian Journal of Behavioural Science, 32, 243-250.

Leman, P.J. \& Tenenbaum, H.R. (2011) Practising gender: children's relationships and the development of gendered behaviour and beliefs. British Journal of Developmental Psychology, 29, 153-157.

Loomis, J.B. \& White, D.S. (1996) Economic benefits of rare and endangered species: summary and meta-analysis. Ecological Economics, 18, 197-206.

Loss, S.R., Will, T. \& MARRA, P.P. (2013) The impact of free-ranging domestic cats on wildlife of the United States. Nature Communications, 4, 1396.

Macartney, S., Bishaw, A. \& Fontenot, K. (2013) Poverty rates for selected detailed race and Hispanic groups by state and place: 20072011. Https://www.census.gov/prod/2013pubs/acsbr11-17.pdf [accessed 25 February 2016].

Mace, G.M., Possingham, H.P. \& Leader-Williams, N. (2007) Prioritizing choices in conservation. In Key Topics in Conservation Biology (eds D. Macdonald \& K. Service), pp. 17-34. Blackwell Publishing, Oxford, UK.

Manfredo, M.J., Teel, T.L. \& Bright, A.D. (2003) Why are public values toward wildlife changing? Human Dimensions of Wildlife, 8 , 287-306.

Martin, C.L. \& Ruble, D. (2004) Children's search for gender cues: cognitive perspectives on gender development. Current Directions in Psychological Science, 13, 67-70.

Martin, C.L. \& Ruble, D.N. (2009) Patterns of gender development. Annual Review of Psychology, 61, 353-381.

Martín-López, B., Montes, C. \& Benayas, J. (2007) The non-economic motives behind the willingness to pay for biodiversity conservation. Biological Conservation, 139, 67-82.

Martín-lópez, B., Montes, C., Ramírez, L. \& Benayas, J. (2009) What drives policy decision-making related to species conservation? Biological Conservation, 142, 1370-1380.

Meine, C., Soulé, M. \& Noss, R.F. (2006) 'A mission-driven discipline': the growth of conservation biology. Conservation Biology, 20, 631-651.

Meuser, E., Harshaw, H.W. \& Mooers, A.Ø. (2009) Public preference for endemism over other conservation-related species attributes. Conservation Biology, 23, 1041-1046.

Miller, J.R. (2005) Biodiversity conservation and the extinction of experience. Trends in Ecology \& Evolution, 20, 430-434.

Monroe, M.C. (2003) Two avenues for encouraging conservation behaviors. Human Ecology Review, 10, 113-125.

Montgomery, C.A. (2002) Ranking the benefits of biodiversity: an exploration of relative values. Journal of Environmental Management, 65, 313-326.

Morse-Jones, S., Bateman, I.J., Kontoleon, A., Ferrini, S., Burgess, N.D. \& TuRneR, R.K. (2012) Stated preferences for tropical wildlife conservation amongst distant beneficiaries: 
charisma, endemism, scope and substitution effects. Ecological Economics, 78, 9-18.

Norton, B.G. (1986) The Preservation of Species: The Value of Biological Diversity. Princeton University Press, Princeton, USA.

Pereira, H.M., Leadley, P.W., Proença, V., Alkemade, R., Scharlemann, J.P.W., Fernandez-Manjarrés, J.F. et al. (2010) Scenarios for global biodiversity in the 21st century. Science, 330 , 1496-1501.

Pimm, S.L., Russell, G.J., Gittleman, J.L. \& Brooks, T.M. (1995)

The future of biodiversity. Science, 269, 347-350.

Possingham, H.P., Andelman, S.J., Burgman, M.A., Medellín, R.A., Master, L.L. \& Keith, D.A. (2002) Limits to the use of threatened species lists. Trends in Ecology \& Evolution, 17, 503-507.

Prokop, P. \& Fančovičová, J. (2013) Does colour matter? The influence of animal warning coloration on human emotions and willingness to protect them. Animal Conservation, 16, 458-466.

Prokop, P. \& Tunnicliffe, S.D. (2010) Effects of having pets at home on children's attitudes toward popular and unpopular animals. Anthrozoos, 23, 21-35.

Redding, D.W., DeWolfF, C.V. \& Mooers, A.Ø. (2010) Evolutionary distinctiveness, threat status, and ecological oddity in primates. Conservation Biology, 24, 1052-1058.

Robertson, S.A. (2008) A review of feral cat control. Journal of Feline Medicine \& Surgery, 10, 366-375.

Scott, D. \& Willits, F.K. (1994) Environmental attitudes and behavior: a Pennsylvania survey. Environment and Behavior, 26, 239-26o.

Serbin, L.A., Powlishta, K.K., Gulko, J., Martin, C.L. \& Lockheed, M.E. (1993) The development of sex typing in middle childhood. Monographs of the Society for Research in Child Development, 58, 1-95.

Sinclair, S., Dunn, E. \& Lowery, B. (2005) The relationship between parental racial attitudes and children's implicit prejudice. Journal of Experimental Social Psychology, 41, 283-289.

Sodhi, N.S., Posa, M.R.C., Lee, T.M., Bickford, D., Koh, L.P. \& Brook, B.W. (2010) The state and conservation of Southeast Asian biodiversity. Biodiversity and Conservation, 19, 317-328.

Stevenson, K.T., Peterson, M.N., Bondell, H.D., Mertig, A.G. \& Moore, S.E. (2013) Environmental, institutional, and demographic predictors of environmental literacy among middle school children. PLoS ONE, 8(3), e59519.

Stevenson, K.T., Peterson, M.N., Carrier, S.J., Strnad, R.L., Bondell, H.D., Kirby-Hathaway, T. \& Moore, S.E. (2014) Role of significant life experiences in building environmental knowledge and behavior among middle school students. The Journal of Environmental Education, 45, 163-177.

Takahashi, Y., Veríssimo, D., MacMillan, D.C. \& Godbole, A. (2012) Stakeholder perceptions of potential flagship species for the sacred groves of the North Western Ghats, India. Human Dimensions of Wildife, 17, 257-269.

Tarrant, M.A. \& Cordell, H.K. (2002) Amenity values of public and private forests: examining the value-attitude relationship. Environmental Management, 30, 692-703.

Teel, T.L., Dayer, A.A., Manfredo, M.J. \& Bright, A.D. (2005) Regional Results from the Research Project Entitled 'Wildlife Values in the West'. Project report for the Western Association of Fish and Wildlife Agencies, Fort Collins, USA.

U.S. Department of Education (2012) National Center for Education Statistics. Https://nces.ed.gov/ [accessed 11 November 2015].

Van Liere, K.D. \& Dunlap, R.E. (1980) The social bases of environmental concern: a review of hypotheses, explanations and empirical evidence. The Public Opinion Quarterly, 44, 181-197.

Veríssimo, D., Fraser, I., Girão, W., Campos, A.A., Smith, R.J. \& MaCmillan, D.C. (2014) Evaluating conservation flagships and flagship fleets. Conservation Letters, 7, 263-270.

Veríssimo, D., Fraser, I., Groombridge, J., Bristol, R. \& MacMillan, D.C. (2009) Birds as tourism flagship species: a case study of tropical islands. Animal Conservation, 12, 549-558.

Waldron, A., Mooers, A.O., Miller, D.C., Nibbelink, N., Redding, D., Kunn, T.S. et al. (2013) Targeting global conservation funding to limit immediate biodiversity declines. Proceedings of the National Academy of Sciences of the United States of America, 110, 12144-12148.

Walia Sharma, R. \& Dasgupta, P. (2009) Marketing to children: a planning framework. Young Consumers, 10, 180-187.

WEISs, E.B. (1990) Our rights and obligations to future generations for the environment. The American Journal of International Law, 84, 198-207.

Wilson, H.B., Joseph, L.N., Moore, A.L. \& Possingham, H.P. (2011) When should we save the most endangered species? Ecology Letters, 14, 886-89o.

\section{Biographical sketches}

KRISTIN FREW is studying the valuation of wildlife species in North Carolina. Her interests include environmental education and human dimensions of wildlife science. Nils Peterson's research focuses on unravelling the drivers of environmental behaviour, particularly in contexts of environmental education, conservation development, and biodiversity conservation conflict. KATHRYN STEVENSON's interests focus on building environmental and climate literacy among elementary to high school students. 